\title{
ERRATUM
}

Torben Dybdahl · Morten Andersen · Jens Søndergaard

Jakob Kragstrup · Ivar Sønbø Kristiansen

\section{Does the early adopter of drugs exist? A population-based study of general practitioners' prescribing of new drugs}

Published online: 4 February 2005

(C) Springer-Verlag 2005

\section{Eur J Clin Pharmacol (2004) 60:667-672}

The currency conversion of Table 2 should read

$1 \mathrm{USD} \backsim 7.38$ DKK or 1 EUR $\sim 7.42$ DKK $(1$ January 2000)

The online version of the original article can be found at http:// dx.doi.org/10.1007/s00228-004-0797-1

T. Dybdahl $(\bowtie) \cdot$ M. Andersen · J. Kragstrup · I. S. Kristiansen Research Unit of General Practice, Institute of Public Health, University of Southern Denmark,

Winsløwparken 19, 3rd, 5000 Odense C, Denmark E-mail: tdybdahl@health.sdu.dk

Tel.: + 45-65501000

Fax: $+45-65111642$

M. Andersen

Research Unit of Clinical Pharmacology,

Institute of Public Health,

University of Southern Denmark,

Winsløwparken 19, 5000 Odense C, Denmark

J. Søndergaard

Research Unit of General Practice,

Faculty of Health Sciences, University of Aarhus,

Vennelyst Boulevard 6,

8000 Aarhus C, Denmark 